\title{
Heavy metal contamination and health risk assessment of mechanically milled delicacy called fufu
}

\author{
Marian Asantewah Nkansah * (D, Patrica-Ivy Agorsor and Francis Opoku
}

\begin{abstract}
Contamination of food by heavy metals is a concern as consumption of contaminated food is one of the most likely human exposure routes to metals. Fufu is a delicacy in Ghana consumed mainly by the Akans. Human exposure to some heavy metals ( $\mathrm{Cr}, \mathrm{Fe}, \mathrm{Zn}, \mathrm{Mn}$ and $\mathrm{Ni}$ ) through mechanically processed fufu consumption was analysed by atomic absorption spectrophotometer and ascertaining consumer awareness of potential exposure by questionnaire administration. A total of 30 milled and un-milled fufu samples (cassava and plantain) were sampled from Bomso, Kotei, Ayeduase, Ayigya and Kentikrono, all within Kumasi. The results showed that Fe and Zn levels after milling were elevated in the range: $2.816-7.297$ and $0.753-7.529 \mathrm{mg} / \mathrm{kg}$, respectively. The concentrations of Fe and Zn were below the Food and Agriculture Organization/World Health Organization (FAO/WHO) permissible limits except Zn concentration at Bomso. Cr, Mn and Ni were below the detection limit (0.05). Hazard quotients and indices were less than the US Environmental Protection Agency's permitted level of one, indicating no possible harm to consumers. Findings from the questionnaire administration indicated a complete lack of knowledge on consumer exposure due to the food processing method.
\end{abstract}

Keywords: Food contamination, Fufu, Heavy metals, Atomic absorption spectroscopy, Health risk assessment

\section{Introduction}

As a typical carbohydrate food crop, cassava grows in soils with marginal nutrition (Aerni 2006). Fresh cassava root contains $75-80 \%$ moisture, $0.70-2.50 \%$ ash, $1.0 \%$ fibre, $0.1 \%$ fat and $2-3 \%$ protein and $32-35 \%$ carbohydrate (Abass et al. 2018). Cassava roots also contain small amounts of $\beta$-carotene, iron and zinc (Gegios et al. 2010). If not properly processed, fresh cassava root undergoes fast spoilage within 48 to $72 \mathrm{~h}$ due to its high moisture content (Ashaye et al. 2005; Awoyale et al. 2018). Processing the roots into various products increases the shelf life and makes transportation to urban markets less expensive (Taiwo 2006). Cassava is processed and consumed in

*Correspondence: maan4gr@yahoo.co.uk Department of Chemistry, Kwame Nkrumah University of Science and Technology (KNUST), Kumasi, Ghana different forms in sub-Saharan Africa (Duah et al. 2016). The processing method includes extracting starch, boiling and pounding, roasting/toasting, drying and milling into flour, fermenting, and peeling (Duah et al. 2016). In Ghana, cassava is consumed as a dried milled product known as kokonte, gari and fufu (Kleih et al. 2013). Fufu is a popular traditional food for most Ghanaians, especially among the Ashanti's (Egyir and Yeboah 2009). It is prepared from the combination of boiled cassava with plantain or cocoyam or cassava alone through pounding in a mortar with a pestle (Otoo et al. 2018).

Heavy metal pollution is one of the major concerns for food safety and security due to its severe detrimental effects on human health and the environment (Motesharrei et al. 2016). Heavy metals enter food through soil, water for agricultural irrigation and materials used during food processing (Huang et al. 
2018; Islam et al. 2018). The presence of heavy metals results in plant accumulation and the intake of contaminated food results in their biomagnification in the human body and are associated with an increased risk of neurological, kidney and cardiovascular diseases (Yang et al. 2019). For optimum yield, cassava requires essential nutrients (iron, manganese, nickel, copper, zinc, chromium, etc.) in trace amounts. Cultivation of food crops in soils contaminated by heavy metals results in their accumulation in the edible parts, which humans later consumed (Amin et al. 2013). Cassava, like most plants, tends to bioaccumulate heavy metals in soil, which can then be transferred up the food chain (Kigigha et al. 2018).

Contamination of food by heavy metals has become an unescapable yield of modern technology, although modern technology has contributed significantly to economic growth over the years (Dabonne et al. 2010). A study carried out on processing equipment revealed that $\mathrm{Hg}, \mathrm{Cr}, \mathrm{Fe}, \mathrm{Mn}, \mathrm{Pb}, \mathrm{Zn}, \mathrm{Co}, \mathrm{Ni}$ and several other metals often appear in processed food, but their concentrations vary (Elekofehinti et al. 2012). Several metals, including $\mathrm{Ni}, \mathrm{Fe}, \mathrm{Mn}, \mathrm{Cu}$ and $\mathrm{Zn}$ in foodstuffs, are vital for biological functions in low concentrations, but excessive concentrations can cause metabolic anomalies (Linder 1991). Heavy metals contamination in gari (Awoyale et al. 2018; Dibofori-Orji and Edori 2015; Kigigha et al. 2018), dried cassava products from Nigeria (Abass et al. 2018), Cassava Tubers, Ogun State, Nigeria (Makanjuola 2016) and fufu, Kumasi-Ghana (Ankar-Brewoo et al. 2020) have been reported from various parts of sub-Saharan Africa. A study carried out on processing equipment revealed that mercury, chromium, iron, manganese, lead, zinc, cobalt, nickel and other metals appear in processed food every day, but concentrations vary greatly (Elekofehinti et al. 2012). The time-consuming and laborious preparation of fufu gradually decreases its consumption in the homes of most career women and men (Johnson et al. 2006; Otoo et al. 2018). Due to lifestyle changes, fufu pounding has been commercialized into processing packages and mechanized within several Ghana communities, including the Ashanti Region. Fufu pounding machines are generally made from steel (Yahaya et al. 2010). Due to the possibility of the mill leaching components to the food or through heavy metal intake from contaminated soil, there is the need to evaluate the concentrations of heavy metals in fufu. This study was carried out because of the lack of data on health risks posed by heavy metals ( $\mathrm{Fe}, \mathrm{Zn}, \mathrm{Cr}, \mathrm{Mn}$ and $\mathrm{Ni}$ ) through fufu intake, particularly those processed from mechanized pounding machines in the Ashanti region of Ghana.

\section{Materials and methods}

\section{Study area}

The research was carried out in five communities around the Kwame Nkrumah University of Science and Technology (KNUST) in the Kumasi Metropolis. Kumasi is in the rainforest region and is about $250 \mathrm{~km}$ north of Accra, the Capital city of Ghana. It lies between longitude 1.30 $-1.35^{\circ}$ and latitude $6.35^{\circ}-6.40^{\circ}$ with an elevation range from 250 to $300 \mathrm{~m}$ above sea level. The communities are Ayigya, Ayeduase, Bomso, Kentikrono and Kotei. These places were selected because of their high patronage by the KNUST community.

\section{Sampling and preparation}

A total of 30 milled and un-milled fufu ingredients (boiled cassava and plantain) were sampled from five communities around KNUST campus in the Ashanti Region. Six of these samples (before and after milling) were collected from three patrons at each fufu milling site into Zip-lock bags, wrapped in polyethylene bags, transported to the laboratory, and kept at ambient temperature. Unmilled samples were separated and homogenized using porcelain mortar and pestle to serve as controls.

\section{Wet acid digestion of fufu samples}

Wet acid digestion was employed to isolate the metals in the food samples from their complex matrices before assessing them with the Atomic Absorption Spectroscopy (AAS). Each $1.0 \mathrm{~g}$ of food sample was digested by heating with a digestion mixture containing concentrated nitric, perchloric and sulphuric acids in a ratio of 2:2:5 in a $50 \mathrm{~mL}$ digestion tube. Each sample mixture was evaporated on a hot plate in a fume hood at $200^{\circ} \mathrm{C}$ for 30 min until the brown fumes disappeared, leaving the white fumes. The clear digests were cooled and diluted with distilled water to the $50 \mathrm{ml}$ mark. Digestion of a reagent blank was carried out parallel with the fufu samples, with the same digestion parameters. Appropriate dilutions were made with deionized water. The heavy metals were analysed using Flame Atomic Absorption Spectrophotometer (Model: novAA400P, Germany). The instrument was equipped with a deuterium lamp corrector and standard air acetylene flame. The mean and relative standard deviations (RSDs) of the spike recoveries for the triplicate analyses were determined (Table 1).

\section{Health risk assessment}

Iron is an essential element required in the blood pigment to help transport oxygen to all parts of the body; however, its excessive intake poses risk to human health (Osweiler et al. 1985). Similarly, $\mathrm{Zn}$ is an essential element that helps wound healing and blood clotting, but its intoxication is known to damage the pancreas, disturb 
Table 1 Linear range, linearity, recovery, limit of detection (LOD) and limit of quantification (LOQ) for the target heavy metals

\begin{tabular}{llllll}
\hline Element & Linear range & $\boldsymbol{R}^{\mathbf{2}}$ & Recovery $\pm \mathbf{R S D}(\%)$ & LOD $\left(\mathbf{m g ~ k g}^{-\mathbf{1}}\right)$ & $\left.\mathbf{L O Q}_{\mathbf{( m g ~ k g}}^{\mathbf{- 1}}\right)$ \\
\hline $\mathrm{Zn}$ & $0.0005-5$ & 0.9998 & $92.36 \pm 6.90$ & 0.27 & 0.39 \\
$\mathrm{Fe}$ & $0.0005-5$ & 0.9999 & $94.58 \pm 9.32$ & 0.16 & 0.25 \\
\hline
\end{tabular}

protein metabolism, and cause arteriosclerosis (WHO 1973). The heavy metal concentrations were used to compute the estimated daily intake of metals (EDI) and hazard quotient (HQ) via fufu intake. Risk assessment is a tool for assessing the likelihood of health conditions or diseases in living organisms exposed to a toxic medium over time. The chronic EDI relating to heavy metal exposure for fufu consumption was calculated according to the following equation (USEPA 1989, 2020):

$$
\mathrm{EDI}=\frac{I R \times C_{i} \times E F \times E D}{B W \times A T}
$$

where $I R$ is the daily $(0.408 \mathrm{~kg} /$ day $)$ fufu consumption rate in Ghana (MFA 2010), $C_{i}$ is the concentration of heavy metal, $E F$ is the exposure frequency (i.e., 365 days/ year), $E D$ is the exposure duration (i.e., 70years) (BorteySam et al. 2015), $B W$ is the bodyweight of $60 \mathrm{~kg}$ (Qing et al. 2015) and $A T$ is the average time of exposure (i.e., 25,550 days) (Bortey-Sam et al. 2015).

The non-carcinogenic health risk assessment for local communities via fufu intake was determined based on HQ for a single element (Eq. 2) and hazard index (HI) for multiple elements (Eq. 3) (USEPA 1989).

$$
\mathrm{HQ}=\frac{\mathrm{EDI}}{\mathrm{RfD}}
$$

where RfD is the oral reference dose of heavy metal. RfD for $\mathrm{Fe}$ and $\mathrm{Zn}$ are 0.7 and $0.3 \mathrm{mg} / \mathrm{kg} /$ day, respectively (USEPA 2015). Exposed population consuming fufu in the study area could be safe during a lifetime, when HQ is $<1$ (USEPA 1989).

The overall non-carcinogenic health risk posed to individuals by heavy metals via fufu intake was evaluated as (USEPA 1989):

$$
\mathrm{HI}=\sum \mathrm{HQ}_{\mathrm{i}}
$$

$\mathrm{HI} \geq 1$ indicates a chance of non-carcinogenic effects, with an increasing likelihood as the value increases, while $\mathrm{HI} \geq 10$ indicates chronic toxic effects (Akoto et al. 2014).

\section{Statistical analysis}

All statistical analyses were performed using IBM Statistical Package for Social Science software for windows (IBM Corp 2011). Pearson's correlation coefficient was used to determine the association between the heavy metals (Kirch 2008). A Probability level of $p<0.05$ was considered statistically significant.

\section{Results and discussion}

\section{Quality assurance/quality control}

As listed in Table 1, the mean and relative standard deviations (RSDs) of the spike recoveries for the triplicate analyses were $92.36 \pm 6.90 \%$ and $94.58 \pm 9.32 \%$ for $\mathrm{Zn}$ and Fe, respectively. All the values were under the recommended control limits of $80-120 \%$ for laboratory control sample recovery and $\leq 15 \%$ RSD. These results showed that the analytical method possesses the required precision and accuracy. The limit of detection (LOD) was 0.27 and $0.16 \mathrm{mg} \mathrm{kg}^{-1}$ for $\mathrm{Zn}$ and Fe, respectively, while the limit of quantification (LOQ) was 0.39 and 0.25 for $\mathrm{Zn}$ and Fe, respectively. The calibration curves for both metals showed good linearity in the concentrations range of $5 \times 10^{-4}$ and $5 \mathrm{mgL}^{-1}$ with $\mathrm{R}^{2}$ ranged between 0.9998 and 0.9999 , which were greater than the acceptable limit (0.998) for the linearity of regression line.

\section{Heavy metal concentration}

Table 2 summarises the heavy metal concentrations in fufu from the study area. The results showed that $\mathrm{Cr}, \mathrm{Ni}$ and $\mathrm{Mn}$ were below the detection limit. The mean concentration of Fe in the un-milled fufu samples ranged between 0.554 and $3.376 \mathrm{mg} / \mathrm{kg}$ at the various communities. $\mathrm{Zn}$ concentration in the un-milled fufu ranged between 0.090 and $5.166 \mathrm{mg} / \mathrm{kg}$. The milled fufu had Fe and $\mathrm{Zn}$ levels ranging from 2.817 to 7.297 and 0.753 to $7.529 \mathrm{mg} / \mathrm{kg}$, respectively. The results show an increase in Fe and $\mathrm{Zn}$ concentration after milling, indicating that the locally fabricated fufu pounding mill added some metal concentrations due to friction, wearing and tearing of the grinding plate as the food samples come in contact (Yahaya et al. 2010). External factors including, anthropogenic sources, can contribute to the uptake of heavy metals by cassava grown at the different sampling sites. The levels of Fe recorded for all the analysed samples were below the Food and Agriculture Organization (FAO)/ World Health Organization (WHO) recommended limit (FAO/WHO 2006), indicating minimal risk of Fe intoxication from consumption of these sources. Mean Zn concentration obtained for the sample from Bomso was above the allowable limit set by FAO/WHO for Zn. Samples 
Table 2 Levels of Fe and Zn in fufu samples before and after milling

\begin{tabular}{|c|c|c|c|c|c|c|c|c|c|c|}
\hline Communities & $\begin{array}{l}\text { Mean Zn } \\
\text { Before } \\
\text { milling }\end{array}$ & RSD\% & $\begin{array}{l}\text { Mean Zn After } \\
\text { milling }\end{array}$ & RSD\% & $\begin{array}{l}\text { Mean Fe } \\
\text { Before } \\
\text { milling }\end{array}$ & RSD $\%$ & $\begin{array}{l}\text { Mean Fe After } \\
\text { milling }\end{array}$ & RSD $\%$ & $\begin{array}{l}\mathrm{FAO} / \mathrm{WHO} \\
\text { limits for } \mathrm{Fe}\end{array}$ & $\begin{array}{l}\text { FAO/WHO } \\
\text { limits for } \\
\mathrm{Zn}\end{array}$ \\
\hline Ayigya & $1.64 \pm 0.08$ & 4.88 & $2.06 \pm 0.59$ & 28.60 & $0.55 \pm 0.14$ & 25.27 & $2.82 \pm 0.76$ & 26.99 & 15 & 5 \\
\hline Bomso & $5.17 \pm 0.52$ & 10.07 & $7.53 \pm 0.94$ & 12.49 & $3.08 \pm 0.80$ & 25.95 & $5.25 \pm 0.87$ & 16.56 & 15 & 5 \\
\hline Ayeduase & $0.09 \pm 0.02$ & 22.22 & $0.91 \pm 0.13$ & 14.32 & $3.38 \pm 0.53$ & 15.70 & $5.23 \pm 0.16$ & 3.06 & 15 & 5 \\
\hline Kotei & $0.38 \pm 0.06$ & 15.83 & $0.75 \pm 0.08$ & 10.62 & $2.49 \pm 0.60$ & 24.14 & $7.30 \pm 0.50$ & 6.85 & 15 & 5 \\
\hline Kentikrono & $0.41 \pm 0.07$ & 17.16 & $3.68 \pm 0.51$ & 13.85 & $1.72 \pm 0.40$ & 23.20 & $5.80 \pm 0.14$ & 2.41 & 15 & 5 \\
\hline
\end{tabular}

${ }^{a}$ All concentrations are in $\mathrm{mg} / \mathrm{kg}$

from all the other communities produced $\mathrm{Zn}$ concentrations below the FAO/WHO permissible limit.

\section{Statistical analysis of heavy metals in fufu}

The results revealed that the study area had a significant positive correlation $(p<0.05)$ between the concentration of $\mathrm{Zn}$ before and after milling (Table 3). The weak positive correlation of $\mathrm{Fe}$ and $\mathrm{Zn}$ indicated the different sources of pollution and the independence on the heavy metal concentrations in all the communities under study.

These groups represent similarities in the origins of heavy metals. To study the qualitative nature of clustering, principal component analysis (PCA) with two components was applied. The PCA of heavy metals shows two components extracted with $88.924 \%$ cumulative percent of the total variance (Table 4).

Out of this, the contribution of factor 1 (PC 1) was $49.188 \%$ of the total variance with high loadings of $\mathrm{Zn}$ before and after milling. PC 2 contributed $39.736 \%$ of the total variance with Fe loading before and after milling. PCA analysis indicates a probability that both $\mathrm{Zn}$ and $\mathrm{Fe}$ before and after milling come from a similar source.

\section{Health risk assessment}

Risk assessment was carried to quantitatively evaluate the likely health risks posed to fufu consumers of Ayigya, Bomso, Ayeduase, Kotei and Kentikrono based on daily dietary intake of heavy metals. Cumulative health effects from the contamination of heavy metals were assessed

Table 3 Correlation for $\mathrm{Zn}$ and Fe concentration in fufu samples before and after milling

\begin{tabular}{lllll}
\hline & Zn Before & Zn After & Fe Before & Fe After \\
\hline Zn Before & 1 & & & \\
Zn After & $0.896^{\mathrm{a}}$ & 1 & & \\
Fe Before & 0.160 & 0.166 & 1 & \\
Fe After & -0.234 & -0.104 & 0.586 & 1
\end{tabular}

${ }^{a}$ Correlation is significant at the 0.05 level (2-tailed) using HI, which is the sum of HQ values. Results for the EDI, HQ and HI of heavy metals are summarised in Table 5.

The amount of $\mathrm{Zn}$ and $\mathrm{Fe}$ ingested in the studies samples was significantly less, as revealed by the estimated daily intake values obtained (Table 4). EDI values ranged from 0.019 to $0.050 \mathrm{mg} / \mathrm{kg} /$ day for $\mathrm{Fe}$ and 0.005 to $0.051 \mathrm{mg} / \mathrm{kg} /$ day for $\mathrm{Zn}$. Based on EDI values for Fe $(17 \mathrm{mg} / \mathrm{kg} /$ day $)$ and $\mathrm{Zn}(20 \mathrm{mg} / \mathrm{kg} /$ day $)$, set by Codex Alimentarius Commission (Åkesson et al. 2015), the levels of EDI for $\mathrm{Zn}$ and Fe in fufu do not pose adverse effects to human health. Fe recorded HQ in the range of 0.027 to 0.071 , while $\mathrm{Zn}$ recorded $\mathrm{HQ}$ values in the range of 0.017 to 0.171 . HI ranged from 0.071 to 0.222 . The HQ and HI of each heavy metal in fufu were $<1$, which indicate that daily exposure is unlikely to pose adverse non-carcinogenic effect on human health due to these heavy metals. Therefore, at the current consumption rate, heavy metals do not pose any considerable individual or combined health risk to the consumers in the studied communities. However, it should be noted that prolonged consumption could lead to extreme accumulation of $\mathrm{Zn}$ and $\mathrm{Fe}$ in the body and cause related health problems. Residents living in these communities and other neighbouring communities should be encouraged not to consume large quantities of milled fufu per day to minimize or avoid excessive accumulation of these potentially toxic heavy metals.

Table 4 PCA for Zn and Fe concentration in fufu samples before and after milling

\begin{tabular}{lll}
\hline & PC 1 & PC 2 \\
\hline Zn Before & $\mathbf{0 . 9 7 7}$ & -0.042 \\
Zn After & $\mathbf{0 . 9 6 3}$ & 0.040 \\
Fe Before & 0.206 & $\mathbf{0 . 8 8 9}$ \\
Fe After & -0.210 & $\mathbf{0 . 8 9 2}$ \\
Total & 1.968 & 1.589 \\
\% of Variance & 49.188 & 39.736 \\
Cumulative \% & 49.188 & 88.924 \\
\hline
\end{tabular}

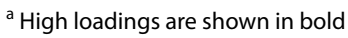


Table 5 Estimated daily intake and hazard quotient and hazard index values for non-carcinogenic assessments for $\mathrm{Zn}$ and Fe in fufu samples

\begin{tabular}{|c|c|c|c|c|c|}
\hline \multirow[t]{2}{*}{ Communities } & \multicolumn{2}{|c|}{$\begin{array}{l}\text { Estimated Daily } \\
\text { Intake }(\mathrm{mg} / \mathrm{kg} / \\
\text { day) }\end{array}$} & \multicolumn{2}{|c|}{$\begin{array}{l}\text { Hazard } \\
\text { Quotients }\end{array}$} & \multirow[t]{2}{*}{ Hazard Indices } \\
\hline & $\mathrm{Zn}$ & $\mathrm{Fe}$ & $\mathrm{Zn}$ & $\mathrm{Fe}$ & \\
\hline Ayigya & 0.014 & 0.019 & 0.047 & 0.027 & 0.074 \\
\hline Bomso & 0.051 & 0.036 & 0.171 & 0.051 & 0.222 \\
\hline Ayeduase & 0.006 & 0.036 & 0.021 & 0.051 & 0.071 \\
\hline Kotei & 0.005 & 0.050 & 0.017 & 0.071 & 0.088 \\
\hline Kentikrono & 0.025 & 0.039 & 0.083 & 0.056 & 0.140 \\
\hline
\end{tabular}

\section{Questionnaire administration outcome}

A survey-based on structured questionnaires was conducted to assess consumers' and mill operators' knowledge on the potential of heavy metal exposure due to mechanical milling of fufu. A total of 30 respondents comprising of 5 operators/owners and 25 patrons took part in the survey. The implication of the responses was considered. Ayeduase, Kotei, Bomso, Kentikrono and Ayigya were the communities where owners/operators and patrons were interviewed. Six respondents were selected from each community.

\section{Gender and age distribution}

Almost all the respondents interviewed were females, contrary to a study conducted in Pakistan (Zeeshan et al. 2017). Considering most respondents, $50 \%$ were between ages 26 and 35, 33\% were between 16 to 25 years and $17 \%$ were between 35 to 55 years of age. This indicates that respondents of 26-35 years could largely be exposed to these heavy metals if safety precautions are not taken.

\section{Educational background}

The highest educational level of the respondents was Senior High School (SHS). The distribution was $46 \%$ for SHS. Respondents with Junior High School (JHS) education were $37 \%$. Only $17 \%$ (five of the respondents: two from Ayigya, two from Kotei, and one from Kentikrono) were of primary education status. Bomso had the highest number of respondents with SHS education.

\section{Knowledge about the chemical composition and potential exposure to heavy metals due to milling}

Since the educational section of the structured questionnaires revealed that all the respondents acquired some level of education, their knowledge on the chemical composition of mechanical mills and the potential of heavy metal exposure due to the milling of fufu was evaluated based on their level of education like food safety knowledge during handling and preparation conducted among consumers in Pakistan (Zeeshan et al. 2017). Despite the level of education, all the respondents did not exhibit any knowledge no the potential of heavy metal exposure due to mechanical milling of fufu. They are also unaware of the chemical composition and the risk of hazardous chemical release during milling.

Most of the respondents do not see the need for knowledge of chemical composition. Some of the respondents also claim that cleaning the mill after daily activity prevents harmful chemicals. The level of knowledge on the mill's chemical composition and the potential of heavy metal exposure due to mechanical milling of fufu is bound to be low if they are not given adequate training.

\section{Conclusion}

The study determined the concentrations of heavy metals in mechanically milled fufu, the potential health risk to consumers, and the awareness of potential exposure to those metals through fufu milling. The outcome revealed an increase in Fe and $\mathrm{Zn}$ concentration after milling, where fufu pounding mills could have released Fe and $\mathrm{Zn}$ metal to the fufu samples. Fe and $\mathrm{Zn}$ levels in the milled fufu were in the range of 2.817 to 7.297 and 0.753 to $7.529 \mathrm{mg} / \mathrm{kg}$ compared to the levels 0.354 to 3.376 and 0.090 to $5.166 \mathrm{mg} / \mathrm{kg}$, respectively recorded before milling. These concentrations were below the FAO/WHO allowable limit of 15 and $5 \mathrm{mg} / \mathrm{kg}$ respectively for Fe and $\mathrm{Zn}$, except for an isolated case of high $\mathrm{Zn}$ concentration at Bomso $(7.529 \mathrm{mg} / \mathrm{kg})$. The EDI of $\mathrm{Zn}$ and Fe was lower than the International Food Standards' (Codex Alimentarius) acceptable daily intake of 17 and $20 \mathrm{mg} /$ day, respectively. The HQ and HI of heavy metals were below the USEPA permissible limits of 1 , indicating no potential risk to consumers. An indication that it is generally safe for consumers in the study area to patronise mechanically milled fufu. The survey also revealed consumers' lack of awareness of the potential of heavy metal exposure due to mechanically milled fufu.

Abbreviations

AT: Average time; BW: Body weight; ED: Exposure duration; EDI: Estimated daily intake of metals; EF: Exposure frequency; FAAS: Flame Atomic Absorption Spectrophotometer; FAO: Food and Agriculture Organization; HI: Hazard index; HQ: Hazard quotient; IR: Ingestion rate; JHS: Junior High School; KNUST: Kwame Nkrumah University of Science and Technology; PCA: Principal component analysis; RfD: Oral reference dose; SHS: Senior High School; WHO: World Health Organization. 


\section{Acknowledgements}

We are grateful to the Department of Chemistry of the Kwame Nkrumah University of Science and Technology, Kumasi-Ghana, for the use of its facilities for this study.

\section{Authors' contributions}

MAN: The originator of the research idea, helped in the experimental design, supervision of research and draft of the manuscript. P-IA: Was involved in the laboratory experiments and draft of the manuscript. FO: Was involved in the research design and draft of the manuscript. The author(s) read and approved the final manuscript.

\section{Authors' information}

MAN: is an Associate Professor of Chemistry at the Department of Chemistry of the Kwame Nkrumah University of Science and Technology, Kumasi-Ghana, with interest in levels and fate of environmental contaminants, health and ecological risk, as well as remediation strategies.

P-I A: is an MPhil candidate of environmental chemistry at the Department of Chemistry of the Kwame Nkrumah University of Science and Technology, Kumasi-Ghana

FO: is a lecturer at the Department of Chemistry of the Kwame Nkrumah University of Science and Technology, Kumasi-Ghana, with interest in inorganic contaminants and method development for environmental remediation and other applications.

\section{Funding}

This research did not receive any specific grant from funding agencies in the public, commercial, or not-for-profit sectors.

\section{Availability of data and materials}

Not applicable.

\section{Declarations}

\section{Competing interests}

Authors have no financial and non-financial competing interests to declare.

Received: 18 May 2021 Accepted: 26 September 2021

Published online: 11 November 2021

\section{References}

Abass A, Awoyale W, Alamu E (2018) Assessment of the chemical and trace metal composition of dried cassava products from Nigeria. Qual Assur Saf Crops Foods 11:43-52

Aerni P (2006) Mobilizing science and technology for development: the case of the Cassava Biotechnology Network (CBN). AgBioForum 9:1-14

Åkesson MT, Point CC, di Caracalla VT (2015) Joint FAO/WHO food standards programme codex committee on contaminants in foods. WHO, Geneva

Akoto O, Bismark EF, Darko G, Adei E (2014) Concentrations and health risk assessments of heavy metals in fish from the Fosu lagoon. Int J Environ Res 8:403-410

Amin N-u, Hussain A, Alamzeb S, Begum S (2013) Accumulation of heavy metals in edible parts of vegetables irrigated with waste water and their daily intake to adults and children, District Mardan, Pakistan. Food Chem 136:1515-1523. https://doi.org/10.1016/j.foodchem.2012.09.058

Ankar-Brewoo GM, Darko G, Abaidoo RC, Dalsgaard A, Johnson P-N, Ellis WO, Brimer $L$ (2020) Health risks of toxic metals (Al, Fe and Pb) in two common street vended foods, fufu and fried-rice, in Kumasi, Ghana. Sci Afr 7:e00289

Ashaye O, Adegbulugbe T, Dawodu O (2005) Evaluation of the processing technologies of cassava chips and flour in Oyo and Ogun states of Nigeria. World J Agric Sci 1:56-58

Awoyale W, Asiedu R, Kawalawu WK, Maziya-Dixon B, Abass A, Edet M, Adetunji MO (2018) Assessment of heavy metals and microbial contamination of gari from Liberia. Food Sci Nutr 6:62-66

Bortey-Sam N, Nakayama SM, Ikenaka Y, Akoto O, Baidoo E, Mizukawa H, Ishizuka M (2015) Health risk assessment of heavy metals and metalloid in drinking water from communities near gold mines in Tarkwa, Ghana. Environ Monit Assess 187:1-12

Dabonne S, Koffi B, Kouadio E, Koffi A, Due E, Kouame L (2010) Traditional utensils: potential sources of poisoning by heavy metals. Br J Pharmacol Toxicol 1:90-92

Dibofori-Orji A, Edori O (2015) Analysis of some heavy metals (Pb, Cd, Cr, Fe, $\mathrm{Zn}$ ) in processed cassava flour (garri) sold along the road side of a busy highway. Arch Appl Sci Res 7:15-19

Duah EA et al (2016) Consumption trends of white cassava and consumer perceptions of yellow cassava in Ghana. J Food Nutr Res 4:814-819

Egyir I, Yeboah B (2009) "Fufu" flour processing in Ghana: costs, returns and institutional support expected to encourage young entrepreneurs. Ghana J Agric Sci 42:157-168

Elekofehinti O, Omotuyi I, Olaremu A, Abayomi T (2012) Heavy metals distribution and lipid profile in the stomach of cow grazed in Akungba-Akoko, Ondo state, Nigeria. Afr J Biochem Res 6:146-149

FAO/WHO (2006) Evaluation of certain food contaminants: sixty-fourth report of the joint FAO/WHO Expert Committee on Food Additives. World Health Organization, Geneva

Gegios A et al (2010) Children consuming cassava as a staple food are at risk for inadequate zinc, iron, and vitamin A intake. Plant Foods Hum Nutr 65:64-70

Huang Y, Chen Q, Deng M, Japenga J, Li T, Yang X, He Z (2018) Heavy metal pollution and health risk assessment of agricultural soils in a typical periurban area in southeast China. J Environ Manag 207:159-168

IBM Corp Released 2011. IBM SPSS statistics for Windows, version 20.0. IBM Corp, Armonk

Islam MA, Romić D, Akber MA, Romić M (2018) Trace metals accumulation in soil irrigated with polluted water and assessment of human health risk from vegetable consumption in Bangladesh. Environ Geochem Health 40:59-85

Johnson PN, Gallat S, Oduro-Yeboah C, Osei-Yaw A, Westby A (2006) Sensory properties of instant fufu flour from four high-yielding Ghanaian varieties of cassava. Trop Sci 46:134-138

Kigigha L, Nyenke P, Izah S (2018) Health risk assessment of selected heavy metals in gari (cassava flake) sold in some major markets in Yenagoa metropolis, Nigeria. MOJ Toxicol 4:47-52

Kirch W (2008) Encyclopedia of public health. Springer Netherlands, Dordrecht

Kleih U, Phillips D, Wordey MT, Komlaga G (2013) Cassava market and value chain analysis, Ghana case study, final report. CAVA 2013:19

Linder MC (1991) Nutritional biochemistry and metabolism: with clinical applications. Elsevier, New York

Makanjuola OM (2016) Evaluation of heavy metals in cassava tubers grown around two major cement factories in Ogun state, Nigeria. Int J Res Stud Biosci 4:26-29

MFA (2010) Accelerated agricultural growth and development strategy in support of Ghana's vision 2020. Ministry of Food and Agriculture, Accra

Motesharrei S et al (2016) Modeling sustainability: population, inequality, consumption, and bidirectional coupling of the earth and human systems. Natl Sci Rev 3:470-494

Osweiler GD, Carson T, Buck WB, Van Gelder G (1985) Clinical and diagnostic veterinary toxicology. Kendall/Hunt Publishing Company, Dubuque

Otoo GS, Essuman EK, Gyimah V, Bigson K (2018) Quality attributes of fufu: instrumental and sensory measurement. Sci Afr 1:e00005

Qing X, Yutong Z, Shenggao L (2015) Assessment of heavy metal pollution and human health risk in urban soils of steel industrial city (Anshan), Liaoning, Northeast China. Ecotoxicol Environ Saf 120:377-385

Taiwo KA (2006) Utilization potentials of cassava in Nigeria: the domestic and industrial products. Food Rev Int 22:29-42

United States Environmental Protection Agency. Risk based screening tablegeneric, summary table. 2015. http://www.epa.gov/risk/risk-based-scree ning-table-generic-tables. Accessed 30 Mar 2021

USEPA (1989) Risk assessment guidance for superfund volume I human health evaluation manual (part A). US Environmental Protection Agency, Washington, DC

USEPA (2020) IRIS assessments. https://cfpub.epa.gov/ncea/iris_drafts/AtoZ. cfm. Accessed 30 Mar 2021

WHO (1973) Trace elements in human nutrition. Technical report series no. 532. World Health Organization, Geneva 
Yahaya M, Ezeh G, Musa Y, Mohammad S (2010) Analysis of heavy metals concentration in road sides soil in Yauri, Nigeria. Afr J Pure Appl Chem 4:022-030

Yang L, Liu G, Di L, Wu X, You W, Huang B (2019) Occurrence, speciation, and risks of trace metals in soils of greenhouse vegetable production from the vicinity of industrial areas in the Yangtze River Delta, China. Environ Sci Pollut Res 26:8696-8708

Zeeshan M, Shah H, Durrani Y, Ayub M, Jan Z, Shah M (2017) A questionnairebased survey on food safety knowledge during food-handling and food preparation practices among university students. J Clin Nutr Diet 3:1-8

\section{Publisher's Note}

Springer Nature remains neutral with regard to jurisdictional claims in published maps and institutional affiliations. 